\title{
中期エジプト語の動詞カテゴリーをめぐって Verb Categories of Middle Egyptian in its Recent Studies
}

\author{
吹田浩 \\ Suita Hiroshi
}

\begin{abstract}
In the preface of his grammar book (1997), Erhart Graefe commented on the development of Middle Egyptian grammar, "die 'Erneuerungszyklen' erinnern an die der Computer." A goal of the present paper is to introduce some recent ideas of Middle Egyptian grammar to Japanese readers.

Many issues regarding Egyptian verb categorization have been discussed since they were proposed by H. J. Polotsky in 1944, 1965 and 1976. In late 1980's, these proposals led a majority of students to share his concept of Standard Theory. Standard Theory held that with a few exceptions, verbs in Middle Egyptian should be transposed into nouns or adverbs. Yet, since it is no longer considered standard since Mark A. Collier denied the existence of adverbialization in 1990, what is "standard" now?

In Japan, Standard Theory has not been clearly understood because no Japanese Egyptologists specialize in Egyptian grammar. First, I will present what has and what has not been established in the Standard Theory to gain a stepping-stone to the newer theory. Among Polotskyan books, I mainly reference those authored by W. Schenkel and E. Graefe, because they have often updated and revised their texts, following the acceptance of latest ideas of the period. Texts by G. Englund (1988), L. M. J. Zonhoven (1992), and J. Hoch (1997) are considered when appropriate.
\end{abstract}

Japanese introductory or popular works by K. Yoshinari (1988) and Sh. Akiyama (1998) are ambivalent with regard to approving the existence of the verbal sentence as A. Gardiner does by following Polotskyan Theory. Today, when the adverbialization of verbs is abandoned, a contradiction between Schenkel and Graefe exists. Schenkel proposes that nominalized verb forms should be regarded as verbal, admitting no room for transposition, while Graefe supports nominalization, which was shared by Ockinga (1998) and Malaise \& Winand (1999).

Another goal of the paper is to organize the confusing grammatical designations

* 関西大学文学部助教授

Associate Professor, Kansai University 
various grammarians have used in different ways in the development of grammar. Complicated terms are also at issue in Japan. "Prospective" is a typical case here. The distinction between prospective and subjunctive has been demonstrated by J. P. Allen (1984) and P. Vernus (1990). Forms that were classified as prospective in the past are now called subjunctive, and the newly approved forms are now referred to as prospective.

The present paper comes from a practical perspective, to clarify the somewhat complicated situation of grammatical development for non-grammarian Egyptologists. It is also apparent in Japan that a study of this kind should presuppose a correct understanding of Structural Linguistics, Transformational Grammar and Cognitive Linguistics.

\section{I. 序}

本稿の目的は, 中期エジプト語の動詞理論の研究の動向を示すことにある。中期エジ プト語の動詞の活用をめぐる解釈は変化が激しく，1980年代にその妥当性を認められる ようになっていた「標準理論」(Standard Theory) も今日では批判にさらされ，新しい修 正が必要とされるようになってきた。本稿では，まず標準理論とはどのようなものであ るのかを確認し, その理論のなかで確定している部分を明確にし, 1990年代になってどの ような点でそれが批判され，崩壊したのかを見て，さらに，新しく考えられている中期 エジプト語の研究の方向を探り出すことにしたい。

今日まで中期エジプト語の標準理論と呼ばれているものは，それ以前に受け入れられ ていたアラン・ガーディナー (Alan Gardiner) の動詞理論を批判したものであり, その骨 子は動詞が名詞と副詞に転換され, 命令などのいくつかの例外を除いて動詞としては使 われないというものである。このようなエジプト語の文法理論は, コプト語の研究から 始まったH . J .ポロツキー (Polotsky) の研究とその影響を受けた一派の文法であり, 本 稿で扱う中期エジプト語についても理論の正当性をめぐる議論はもはや終わり, 細部の 分類などの議論を続け, 新しい知見をつけ加える段階になっていると思われていた。し たがって1980年代の後半になってからは，体系的な記述をする文法書がやっと現れてく るようになってきていた。

しかし，標準理論は1990年にマーク・コリアー (Mark Collier) によって批判されるこ とになった。その結果は，その理論の二柱のひとつである動詞の副詞への転換を否定し， 動詞文を復活させるという劇的なものであった。このような考え方は, ヴォルフガング・ シェンケル (Wolfgang Schenkel) やエルハルト・グレーフェ (Erhart Graefe) によって 受け入れられたことによって，彼らの新しい考え方が学界において一般的になりつつあ 
るように思われる。

今や二柱のひとつを失った標準理論は乗り越えられたというべきであるが，動詞活用 の分類の枠組みについては, 結果として変化しなかった。否定された副詞化の動詞は, 動詞文に移行することによってそのまま存在しているからである。この意味でポロッ キ一学派の理論は，大きな修正を受けながらもさらに成長しつつある。

このような新しい研究の動向を紹介するのに加えて, 本稿にはもうひとつの目的があ る。このような中期エジプト語文法をめぐる議論がなされるなかで, 研究者のあいだに 用語をはじめとして相当に混乱が起こっており，実際の文献の解読にたずさわる研究者 をはなはだ困惑させている。そこで本稿では, 現時点での動詞の分類の枠組みにかかわ る範囲のなかで研究者を悩ます用語の混乱を整理してみる。日本においても, 吉成薰

(1988), 秋山慎一（1998）の文法書, 西村洋子（1998）の単語集が公刊されているが, 混乱は同じように見られる。

なお本稿では，ヒエログリフの文献解釈に必要な合意点を確定するという実際的な観 点から行うために, ポロツキーの論考にくわえて, 学界動向の指標となるシェンケルと グレーフェの文法書を中心にして論を進め, 考察の対象は動詞の基本的な活用形に限定 する。

\section{II. 標準理論}

現在，標準理論と言われているものは，Polotsky（1944）（1965）（1976）を中心にして 形成されてきた学派の理論である。多くの議論がなされていたが，1980年代の後半より 個々の議論を体系化した文法書が現れるようになってきた。なかでも，シェンケルは1987 年以来 4 回, グレーフェも1987年以来 4 回の文法書の改訂をおこなっており, Schenkel （1987）（1991）（1997）とGraefe（1987）（1997）は学界の動向をよく反映している。 中期エジプト語の標準理論とは, 例えば Depuydt（1983）[p. 46] が述べるように, 動 詞は, 名詞と副詞に転換され, 命令法などのいくつかの例外を除いて動詞としては使わ れないというものである。まずこの原理が生まれてきた過程を見た上で, この標準理論 の枠組みを確認し, 次いで研究者のあいだの合意点をシェンケルやグレーフェなどの文 法書の中から見いだしてみたい。

まず Polotsky（1944）は，コプト語の第二時制 (Second Tenses) が実は動詞の名詞化 であることを示し，中期エジプト語では $m r r . f$ 形が名詞として扱われることを示した。 さらに, この mrr.f形を現在時制での名詞化とした上で, 形態に変化を示さない $m r . n . f$ 形と $m r . f$ 形も名詞節となりうることを認め, 前者を過去時制での名詞化, 後者を未来時 制での名詞化とした。 
次いで，動詞の副詞化について述べたのが Polotsky（1965）である。Polotsky (1944) の段階で叙述形 (forme prédicative) とされていた $s d m . f$ と $\underline{d}$ dm.n.fが, 副詞相当語句と 統語上同じ位置で交換可能であり，代入ができる関係にあることから，それらが副詞に 転換されているとした。これによって, 標準理論の 2 つの柱, つまり, 動詞の名詞化と 副詞化が出そろったことになる。

しかしこのことは, 中期エジプト語では, 後期エジプト語, 民衆語, コプト語などと 異なって動詞は動詞のままでは文を構成できないことを意味する。叙述の文は, 助詞と 副詞化された動詞の組み合わせによってつくられる。文法的には，これは副詞文の形で ある。したがって，「動詞文は死んだ」(Depuydt（1983）[p.41]）とされ, 動詞文は存在 しないことになった。

例外的に動詞文と認められていたのは, 命令法, sdm.in.f 形, $s \underline{d m} . h r . f$ 形, $s \underline{d m . k J . f}$ 形, 古い直説法 (Old Indicative) で使われる場合のみである。したがって, 通常に「動詞 文」という場合は，助詞と結びついて複合形の形を取る場合にのみ使われることになっ た。これらの点については, Schenkel (1987) [p.157f., p.182] が指摘するところである。 この点で, 吉成 (1988) [p. 45] と秋山（1998）［テキスト編 p. 44f., p. 49] が, sdm.f 活用形と $s \underline{d} m . n . f$ 活用形に動詞文を想定した分類をしているのは，それらが根本におい てはガーディナー文法の枠組み (Gardiner (1957) [p. 34f.]) から離れていないことを意 味している。

Polotsky (1976) は, 名詞と副詞への品詞の転換を軸にして動詞の多様な形態を統合し ようとしたものであり，これによって標準理論は, Depuydt（1983）[p. 17］の言葉をか りれば，「いくぶん決定的な性格を受けることになった」。この時点で, 中期エジプト語 の動詞文類の枠組みに関しての理論が完成したと言える。

この後10年にわたって盛んに個々の議論がなされ, その成果が文法書の形になって現 れることになる。Schenkel (1987), Graefe (1987), Englund (1988), Zonhoven (1992), Hoch（1997）などの文法書である。日本においても，吉成（1988）と秋山（1998）が公 刊された。

標準理論で研究者間に細部にいたるまでの見解の完全な一致は見たことはなく，した がって完成した標準理論は存在しないが, 理論的なパラダイムは次頁の表のように示さ れるであろう。

次頁に見るように, 動詞は, 名詞と副詞という品詞と, 直説法と仮定法という法によっ て大きく区分され，さらに，直説法は時制・相・動作の様態によって細分される。これ に，古い動詞の生き残りとされる古い直説法が加わる。これが標準理論の動詞区分の理 論上の出発点である。 


\begin{tabular}{|l|c|c|c|}
\hline \multicolumn{2}{|c|}{} & 名詞化 $(\mathrm{A})$ & 副詞化 (B) \\
\hline \multirow{4}{*}{ 直説法 $(\mathrm{C})$} & 過去 $(\mathrm{D})$ & $(\mathrm{G})$ & $(\mathrm{H})$ \\
\cline { 2 - 4 } & 現在 $(\mathrm{E})$ & $(\mathrm{I})$ & $(\mathrm{J})$ \\
\cline { 2 - 4 } & 未来 $(\mathrm{F})$ & $(\mathrm{K})$ & $(\mathrm{L})$ \\
\hline 仮定法 $(\mathrm{M})$ & $(\mathrm{N})$ & $(\mathrm{O})$ \\
\hline
\end{tabular}

古い直説法 $(P)$

( Q)

現実には，研究者のあいだで多様な用語が使われ，研究の進展につれて混乱が起こっ ている。以下にこの点を整理しておきたい。

標準理論では，動詞は，名詞化 (A)されるか，副詞化 (B)される。Polotsky（1976）[p. 1]は,これらにあたるものを Formes Nominales と Formes Adverbiales (Circonstancieles) と呼んでいる。Schenkel (1987) [p.81] では,これらは substantiviert と adverbialisiertであり，Graefe (1987) [p. 88] では，Substantivisch と Adverbialである。 ここで見られる Noun（名詞）と Substantive（実詞）という用語については，現代言 語学辞典（1988）[p. 649］によれば，フランス語圈では nom が多く，ドイツ語圈では Substantiv が一般的なようである。厳密にはそれぞれの用語には歴史的な背景があり， また研究者によっても用法が異なっているが，一般的にはどちらも名詞と考えてよいで あろう。

名詞形は, That-Forms と呼ばれることも多い (e.g. Englund (1988) [p. 37])。また, この名詞形の発見の経緯から Second Tense Forms (e. g. Hoch（1997）[p. 167]）と呼ば れたり，副詞相当語句を強調するというその機能から Emphatic Forms（強調形）と言わ れることも多い。強調形という名称は，Polotsky（1965）[p. 81] 自身が time-honoured name と呼ぶように，よく使用されている。

副詞化（B)には，上記の Polotsky（1976）をはじめ, Circumstantial Forms (状況形) という呼称が用いられることも多い。これは, 副詞化された活用形が名詞相当語句によっ て強調される状況節として使われるためにつけられた名称である (e. g. Hoch (1997) [p. 37f.])。

いずれにせよ，上記の表のような枠組みを考えるならば，標準理論では品詞の転換に ついては名詞化と副詞化という名称の方がすっきりするであろう。

法については, 直説法 $(\mathrm{C})$ と仮定法 $(\mathrm{M})$ に分類するのが, 標準理論のなかでも新しい文 法書では定着している。Polotsky（1976）をはじめ，当初はProspective という用語を 
もって仮定法と末来時制をひとまとめにして呼んでいた。Prospective とは, エジプト学 で用いられる用語であり，展望形・展望相・展望時制・展望法とでも訳されるであろう。 本来は，Gunn（1924）[p.1] が関係形と分詞に関して用いたものであり,「過去, 現在, あるいは未来といったような時間の観点に対して比較的に未来である，あるいは潜在的 である出来事への言及」に使われるとされる。要するに, 法なのか時制や相なのかが曖 昧な用語であった。

この Prospective と呼ばれていたものに直説法と仮定法での 2 つの形があることを古 期エジプト語に確認したのは，Allen（1984）[pp. 152-60］である。そしてこれを中期エ ジプト語の段階に確認したのが Vernus（1990）[pp. 121-36] である。したがって，文法 書のなかでも新しい Schenkel (1987) [p. 81], Graefe (1997) [p. 82], Zonhoven (1992) [p. 102 f.], Hoch (1997) [p. 220] らは，これらを区別している。一方で, Englund (1988) は両者を区別しておらず，グレーフェも1987年の段階ではまだ新しい形を認めていな かった。また後述するポスト標準理論では，当然，両者を区別している。Ockinga (1998) [pp. 42-44], Malaise \& Winand（1999）[pp. 370-83] である。

ここで注意すべきは，2つの形に分かれた際，従来の Prospective の形が仮定法(M) とされるようになり, Prospective という語が新たに未来時制(F)の形のために使われ ることになったということである。すなわち，同じ Prospectiveが，両者の区別を認めな い Graefe (1987), Englund (1988), Hoch（1997）では仮定法(M)を指し，その区別を 認める Schenkel (1987) [p. 81], Graefe (1997) [p. 82], Zonhoven (1992) [p.102f.], Ockinga (1998) [pp. 42-44], Malaise \& Winand (1999) [pp. 370-83] では新発見の未 来時制 $(\mathrm{F})$ を意味するのである。以下では必要に応じて, 展望法 (旧), 展望時制 (新) とし てこれら 2 つの用法を区別する。

直説法は，過去 $(\mathrm{D})$ ，現在 $(\mathrm{E})$ ，未来 $(\mathrm{F})$ の 3 つに区分される。これらは，時制，相， 動作の様態 (Aktionsart)の概念が込み入って混乱している。もともとこれらは, 現代言 語学辞典 (1988) [p. 21, p. 674f.] にもあるよjに, 多くの言語では厳密には区別できず, 言語学では難しい問題とされている。このことは，古代エジプト語にもあてはまる。

多くは，相の用語である完了，未完了に分けた上で，時間的に先であることを意味す るProspective を加えている。Polotsky（1976）[p.7] が， inaccompli，accompli, prospectif としているのに始まり，Schenkel（1987）[p. 81］の Perfektiv, Progressiv/ Imperfektiv, Prospektiv, Graefe (1987) [p. 88] の Perfektiv, Progressiv, Prospektiv といった具合である。

完了や未完了といった相の用語が多いのは, 古代エジプト語の研究がセム系言語との 関連で考えられたことがあったためであろう。実際には, ポロッキー自身が1944年には， 
Passé, Temps indéfini, Futur (Prospectif) と分類している [p. 93] など，相や時制の用 語の区別は必ずしも厳密になされているわけではない。

むしろここで問題となっているのが相対的時間であることは, Gardiner (1957) [p. 160] などに広く認められている。例えば, Englund (1988) [p. 31] の言葉を引用すれば，「し かしながら, 動詞行為の時間は, 話者の時間とは関係なく, 別のある行為に対して先立っ ている, 同時である, 遅れているとも考えられるのである」。これが, 相対的な過去, 相 対的な現在, 相対的な未来である。このような意味に限定した上で, 筆者は上記の表で 過去・現在・未来と区分した。Graefe (1997) [p.68］は動作の様態にも相当の注意を払っ て細分しているが，枠組みとしては変わらないと考える。

なお，枠組みにかかわる問題として，展望法(旧)や仮定法の品詞の問題がある。これ が名詞の性格をもっていることは研究者のあいだに異論はない。これにくわえて理論の 上では，副詞形 $(O)$ の存在が予想されるべきである。実際に, Polotsky（1976）は疑問 符つきながら，その存在を想定し，「『目的節の役割を果たす』“sdm.f”展望法について語

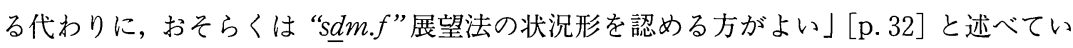
る。すなわちここでは, 副詞の位置に現れる形が, 品詞として副詞であるのか, あるい は名詞形が用法の上で副詞として使われているのかということが問題となっているので ある。多くの文法書は, この問題に明示的には触れていない。くわえて, 展望法(旧), 展望時制 (新), 仮定法を区別するという問題も関係して, 状況は大変に錯綜している。

Schenkel (1987) では, 展望時制(新) と仮定法の両方に副詞形を認める部分 [p. 81, p. 177] と展望時制 (新)に認めながらも仮定法にはその区別に触れない部分 [p. 163 f.] とが 混在しているが，否定形の記述 [p. 173] からみて仮定法にも副詞形を想定しているよう である。Graefe (1987) [p. 88, p.94f.] は，展望法(旧)に両形を認めている。もっとも， シェンケルの解釈には曖昧なところがある。彼は, 1991年になると, 展望時制 (新)には名 詞化と副詞化という区分 [p. 86] と, 名詞化と動詞形という区分 [pp. 180-82] を並存さ せており，また仮定法については2つの形に分けている [p. 203] が，明確な説明がなく， 訳語 [p. $199 \mathrm{f}$. ] から判断すれば，おそらくは名詞化と動詞に分類し, 副詞形を放葉して いる [p. $86 \mathrm{f}$.$] ように見える。$

Englund（1988）は，展望法(旧)が名詞的および副詞的な用法 [p. 36] で使われると述 べ，副詞的な例 [p. 40］をあげている。Hoch（1997）は，展望法(旧)の名詞的性質を強 調している [p. 87] ので, 副詞化については用法とみなしている [p. 169]ように思われ る。展望時制(新)には, 名詞的性質しか認めていない [p. 156, p. 220]。Zonhoven (1992) の立場は，「たしかに Prospective $s d m . f(\S 41)$ はおそらくは強い名詞的な性格をもって いるが, 前置詞の後ろに現れなくても状況的な機能を行使しうる」[p. 78] というもので 
ある。彼の Prospective $s \underline{d m} . f$ は, 展望時制(新)と仮定法を含むものである。以上の三者 は，副詞への転換ではなく，副詞的な用法とみなしている。彼らは，名詞化についてさ えも, 名詞的な「用法」や「性格」という表現にとどめ, 歯切れが大変悪い。

古い直説法 $(\mathrm{P})$ と呼ばれるものは, 古期エジプト語からの生き残りとされ, その用法 は限られている。この名称は, Hoch (1997) [p. 120, Appendix 1]のものである。Polotsky (1976) [p. 46] は，「文字どおり動詞的なカテゴリー（叙述型）」をあらわす形としてい るが，特に名称は与えていない。Schenkel (1987) [p. 161] は，これが完了の意味を持っ ているため, perfective Indikativ と呼んでいる。グレーフェは, 当初これに触れていな かったが，1997年になって (historisches) Perfekt [p. 82] とした。Ockinga (1998) [p. 41] の (Historic) Perfect, Malaise \& Winand (1999) [p. 344] の perfectif $s \underline{d m . f は, ~ こ ~}$ れと同類である。他に, Zonhoven (1992) [p. 105f.] が Indicative sdm.fとしている。 Englund (1988) は, 何も触れていない

最後に, 日本の三者の用語を上記の表に対応させてみよう。吉成（1988）[pp. 81-84] では, 直説法 $s \underline{d m} . f$ 形=古い直説法 $(\mathrm{Q})$, 状況 $s \underline{d m} . f$ 形=直説法現在時制副詞化 $(\mathrm{J})$, 未然 $s \underline{d}$ m. $f$ 形=仮定法 $(\mathrm{M})$, 強調 $s \underline{d}$ m. $f$ 形=直説法現在時制名詞化 (I ), 強調 $s \underline{d m} . n . f$ 形=直説法過去時制名詞化 $(\mathrm{G})$, 状況 $s \underline{d m} . n . f$ 形 = 直説法過去時制副詞化 $(\mathrm{H})$, 秋山

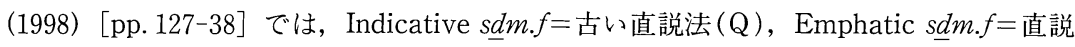
法現在時制名詞化 ( I ), Prospective $s \underline{d} m . f=$ 仮定法 $(\mathrm{N})$, Circumstantial $s \underline{d} m . f=$ 直説法 現在時制副詞化 $(\mathrm{J})$, emphatic $s \underline{d}$ m.n. $f$ 二直説法過去時制名詞化 $(\mathrm{G})$, circumstantial $s \underline{d m} . n . f=$ 直説法過去時制副詞化 $(\mathrm{H})$, 西村 (1998) [p. $140 \mathrm{f}$. ] では, 状況形=直説法現在 時制副詞化 $(\mathrm{J})$, 未然形 $=$ 仮定法 $(\mathrm{M})$, 体言形二直説法現在時制名詞化 $(\mathrm{I})$, 条件形=直 説法未来時制名詞化 $(\mathrm{K})$ になるであろう。西村（1998）は，sdm.n.f形について「状況・ 体言・条件形」 [p. 138] を認めている。前 2 者は, 直説法過去時制副詞化 $(H)$ と直説法 過去時制名詞化 $(G)$ にあたる。吉成 (1988) は, 出版年から当然のことながら, 直説法未 来時制 $(K)(L)$ が脱落している。同じことは, 秋山（1998）にも言える。西村 (1998) は, 直説法未来時制名詞化 $(\mathrm{K})$ に触れる一方で, sdm.n.f 形に筆者の分類にはない条件形を

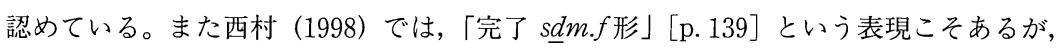
古い直説法 $(\mathrm{Q})$ を明確には認めていないようである。

\section{III. 動詞文の復活——副詞への転換の否定}

Depuydt（1983）[p. 51］が指摘しているように，標準理論への疑問は「強調形の名詞 的な性格にではなく，むしろ副詞文パターンに対して向けられているのが注目に值す る」。そして1990年になると,コリアーが発表した論文が副詞への転換を決定的に否定す 
ることになった。

彼が副詞への転換を否定する手がかりとしたのは, $m k や i s t$ という小辞のあとに現れ る活用形であった。これらの小辞のあとには，多様な形があらわれるが，本論で問題と なる $s \underline{d m} . f$ 形と $s d m . n . f$ 形では, 名詞形と副詞形の両方があらわれている。

まず, 彼があげる副詞形の例を以下に示す。それぞれの例文の前にある番号は, Collier

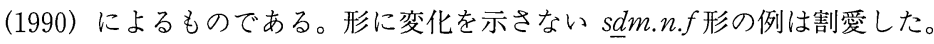

(8) $m k m s n . k \underline{h r d w} 3$

See, three children have been born to you.

(9) mk wi ly.kwi

See, I am come.

(10) $m k n$ wd.tw irt mnt iry $n$ t亏 c wt špsst

See, to do the like thereof to the august herd has not been commanded.

(11) $m$ tn $n$ mว弓ว.n.tw bว w iry

See, the power thereof cannot be seen.

例の $(8)$ は受身の $s \underline{d} m(w) . f$ 形であり, $s \underline{d m} . f$ の副詞形に対応する形である。 $(9)$ は, 移動の動詞の状態形であり，これも $s d m . f$ の副詞形に対応する。(10)と (11)の例は,

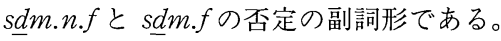

以上の例には, 副詞形の $s \underline{d m} . f$ 形, つまり, 状況 $s \underline{d} m . f$ 形があげられていない。彼自 身は,「状況 $s \underline{d} m(. f)$ 形は, $i w . f \underline{d} \underline{d} m . f$ のパターンを別にして, 文語の中期エジプト語の 主節には特に一般的なわけではない」と述べている。しかし，状況から考えて，副詞形 の存在は認められてよいであろう。

標準理論が名詞形や副詞形を確定するために用いる方法は,「代入」(substitution) とい う方法である。すなおち, $s \underline{d m} . f$ 形や $s \underline{d m . n . f}$ 形が名詞相当語句や副詞相当語句の位置に 現れ，それらの統語論上の役割を果たすことを確認するのである。

では, $m k や i s \underline{-}$ のあとにあらわれる $s \underline{d} m . f$ 形の場合はどうであろうが。副詞の位置に現 れているであろうか。Collier (1990) は, これをきわめて巧妙にも, sdm.f形や $s d m . n . f$ 形の位置に, 逆に明確に副詞的性格をもつ語句が現れるかどうかによって検証しようと した。

(16) $* m k m p r$

* See, in the house.

(17) * mk ḩr-ntt š̌ $m p r$

* See, because the scribe is in the house.

(18) *mk hr-ntt həb.i tw r niwt 
* See, because I am sending you to the town.

以上のような例はありえない。すなはち, $m k$ の後ろには副詞相当語句は現れないのであ る。したがって, sdm.fの副詞形とされていたものが副詞への転換であるとは考えにくく， 品詞を転換しないで使われている動詞として考えるべきであろう。

さらに $m k$ の後ろには, 単体では名詞相当語句もまた現れない。以下の (19)と (21)の例 も文として成り立たない。

(19) * mk ntt sš $m$ pr

* See, that the scribe is in the house.

(20) mk irr.k rirt h̆ $n^{c} . i$

See, that you will do is to act with me.

(21) * mk irr.k

*See, that you will do.

しかし，(20)の例は主節パターンとして可能である。すなわち以上のことは， $m k$ のと に現れるのは，単独の副詞相当語句でもなく，単独の名詞相当語句でもなく，主節が現れ るべきであり，したがって名詞化されていない活用形が現れるならば，それは動詞にちが いないことを示している。そしてこのことはさらに，動詞の副詞化の存在を全体的に疑わ せるのである。このように，コリアーの考え方はきわめて明快である。

\section{IV. ポスト標準理論の動き}

以上に見てきたように，標準理論は 2 つ柱のひとつを失って崩壊した。それでは，現 在我々は中期エジプト語の動詞をどのように考えるべきであろうか。この数年にポスト標 準理論の文法書がいくつか公刊されてきた。Schenkel（1997）とGraefe（1997）にくわえ て, Ockinga (1998) と Malaise \& Winand（1999）の文法書である。彼らは，新しい動詞 の理解に関してシェンケルとグレーフェとは考え方が異なっている。

Graefe (1997) [p.68] の考え方は，もうひとつの柱の名詞化は残っており，否定された 副詞への転換の代わりには動詞がそのまま動詞文として使われるというものである。 Ockinga (1998) [p. 80] と Malaise \& Winand (1999) [p. 235] も同じく名詞化を存続さ せておりこれがもっとも単純な考え方であろう。

一方, Schenkel (1997) は，副詞への転換だけではなく，名詞への転換も否定している。 彼は，「もっともすっきりする解決法は，明らかに，今となっては名詞的な動詞形も動詞的 な動詞形に指定しておくことである」 [p. 24] と述べている。

たとえば， stt bə.i $m$ rmt という文は，従来の標準理論では，stt 「性交すること」とい う名詞化された動詞が副詞相当語である「人々と」という部分を強調していると解釈さ 
れ「私のバーが性交するのは, 人々とである」と訳されてきた。しかし, Schenkel (1997)

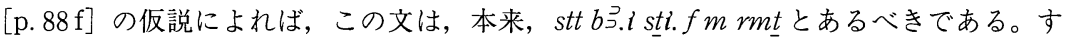
なわち, stt はアオリストの動詞として先置されており，その結果，重複した sti. $f$ の部分 が省略されたと仮定している。したがって, 彼はこの文を「省略(文)構造」あるいは「重 音脱落(文)構造」と呼んでいる。

いずれの考え方が受け入れられていくことになるのかは，まだ明らかではない。シェ ンケルの文法書は，展望時制と仮定法の区別を最初に取り入れるなど常に研究の最先端 にあった。したがって彼から目を離すことはできないが，大勢は，グレーフェのように， 名詞への転換は認める方向にあるように思われる。もしシェンケルの説を認めようとす るならば，後期エジプト語，コプト語，民衆語の文法ですでに認められている名詞化を もゆくゆくは否定してゆくことになり，問題がさらに大きくなる。いずれにせよ，シェ ンケル説の検証は先の話であろう。

以上をふまえてまだ残っている問題は, 展望時制(新), 仮定法の品詞転換の問題であ る。品詞の転換を一切認めない Schenkel（1997）は，1991年の標準理論を焼きなおした 分類表 [p. $208 \mathrm{f}$. ] があるにせよ，この問題からは解放されるであろう。一方，名詞への 転換を認める研究者の見解も一様ではない。Graefe (1997) [p.87,p.89f.]は, 展望時制 （新）と仮定法の両方に名詞化と動詞の両方を認めている。その他，Ockinga（1998） [p. 80]も展望時制(新) と仮定法の両方に名詞化と動詞の両方を認めているが, Malaise \& Winand (1999) [p. 235] は, 名詞化は展望時制 (新)と仮定法の両方に認めるが, 動詞形 は仮定法にしか認めていない。結局のところ，この問題は現時点でまだ決着していない と思われる。

現時点で想定される動詞の活用を次頁の表にまとめてみた。もちろん，その表が完全 であるわけではなく，いくつかの分類では見解が分かれている。また，否定にも相応の 形がある。それらを個々に論じることは本稿の枠を越えることになるであろう。

ひとつだけあげるならば，直説法過去時制は形態に変化を示さないために名詞化と動 詞を区別せずに示されていたが，現在は rdi.n.fと di.n.fに関して何らかの区別をする ようになってきている。Graefe (1997) [p. 68], Schenkel (1997) [p. 172], Ockinga (1998) [p. 38], Malaise \& Winand (1999) [p. 357] などである。

\section{V. 結}

中期エジプト語の文法理論の変化は大変に早い。10年ほど前より標準理論にのつとつ た「新しい」文法書が出始めたかと思うとすぐに, 次のもつと新しい考え方に主流が移つ ている。Graefe (1997) [Vorwort] は，「更新の周期はコンピュータのそれを思い出させ 


\begin{tabular}{|c|c|c|c|c|c|}
\hline & & \multicolumn{4}{|l|}{ 名詞化 } \\
\hline & & 3ae inf 2ae gem $\quad \mathrm{d} d l \quad m \supset \supset \quad \ln l$ & $w n n$ & $i w$ & $m s \underline{d l}$ \\
\hline \multirow{3}{*}{$\begin{array}{l}\text { 直 } \\
\text { 説 } \\
\text { 法 }\end{array}$} & 過去 & $s \underline{d} m n f \quad$ irnf $\quad k b b n f \quad$ rdl $n f \quad m \Xi n f \quad \ln n f l i n f$ & $w n . n . f / w n f$ & iw $n f / l y n f$ & $m s \underline{d} n f$ \\
\hline & 現在 & sqdm.f $\quad$ irrf $\quad$ kbb.f $\quad$ dd.f $\quad m \ni \ni f / m \ni f$ inn $f$ & $w n n f$ & lw fllww.f & $m s \underline{d d} f$ \\
\hline & 末来 & 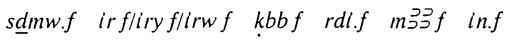 & wnn.f & $i w f$ & $m s \underline{d} f$ \\
\hline \multicolumn{2}{|c|}{ 仮定法 } & sdim.f $\quad$ irfliryf $\quad k b f \quad$ di.f $\quad m \Xi . f / m \supset$ n.f int.f & $w n . f$ & lwt $f$ & $m s \underline{d} f$ \\
\hline
\end{tabular}

\begin{tabular}{|c|c|c|c|c|c|}
\hline & & \multicolumn{4}{|l|}{ 動詞 } \\
\hline & & 3ae inf. 2ae gem $r d l \quad m \supset \supset \quad \ln l$ & $w n n$ & iw & $m s \underline{d} l$ \\
\hline \multirow{3}{*}{$\begin{array}{l}\text { 直 } \\
\text { 説 } \\
\text { 法 }\end{array}$} & 過去 & $s \underline{d m} . n f \quad$ irnf $\quad k b b n f \quad$ dinf $m \supset$ $n f$ inn.f/linf & $w n . n f / w n f$ & - & $m s \underline{d} n f$ \\
\hline & 現在 & 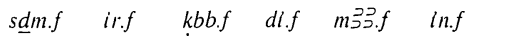 & $w n f$ & lw f/ly.f & $m s \underline{d} f$ \\
\hline & 未来 & 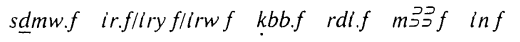 & $w n n f$ & $\operatorname{lwf}$ & $m s \underline{d . f}$ \\
\hline \multicolumn{2}{|c|}{ 仮定法 } & sdm.f $\quad$ irfliryf $\quad k b f \quad$ di.f $\quad m \supset$ f/mכn $f$ int.f & wn.f & iwt.f & $m s \underline{d . f}$ \\
\hline \multirow{2}{*}{\multicolumn{2}{|c|}{ 古い直説法 }} & 3ae inf. 2ae gem. rdi mつ弓 $\ln i$ & $w n n$ & lw & $m s \underline{d l}$ \\
\hline & & 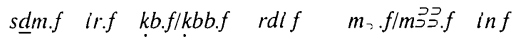 & $w n f$ & $i w . f / l y . f$ & $m s \underline{d} . f$ \\
\hline
\end{tabular}

る」と述べている。この変化の早い中期エジプト語文法理論の大きな変化を紹介するた めに, 本稿では, 1980年代の後半より現れた標準理論に則った文法書から先ず, 標準理論 での合意点を確認し, それが今日いかなる点で崩壊し, 乗り越えられていったか, そし て現時点での中心的な考え方を探り出してみた。

標準理論は, 二本の理論上の柱のうちのひとつである副詞への転換が否定されたこと によって崩壊した。しかし，副詞化のかわりに動詞がそのまま認められることになって， ポロツキー学派の理論はさらに成長していると言える。このなかで多様な議論がなされ, 多くの混乱も起こっている。文法用語の混乱に始まり, 時制・相・動作の様態, 法や品 詞の区別などの範疇の設定の問題, さらには個々の動詞の分類などの混乱である。同様 なことは, 日本語の文献にもあてはまる。本稿では, 学界の動向に敏感なシェンケルや グレーフェの文法書を中心に利用して文献を読む上で必要な動詞のカテゴリーの枠組み を明確にしたうえで，研究者のあいだの現時点での合意点を明らかにしようとした。

古代エジプト語の研究は, 当然のことながら言語学一般の研究と密接に関連して行わ れてきた。それゆえに，言語学の大きな潮流はすべてエジプト学にも反映されており， 
欧米の文法書はまるで魔法の呪文がならんでいるかのようである。代表的なものをあげ れば，ポロツキーの構造主義，Junge（1978）の変形生成文法である。文献を対象とする エジプト学者にも言語学の知識が必要であるが，今後はコリアーのように認知言語学の 知識が必要となってくるであろう。

また，用語の混乱はこれからも避けがたい。例えば, Schenkel（1997）は Generalis

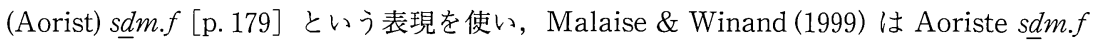
[p. 365] という用語を用いる。ここでいうアオリストとは，実は直説法現在の名詞化と 直説法現在の動詞をそれぞれ指しているのである。

\section{参 考 文 献}

Allen, J. P. 1984 : The Inflection of the Verb in the Pyramid Texts, Malibu.

Collier, M. 1990 : "The Circumstantial $\underline{s} \underline{d} m(. f) / s \underline{d m . n}(f)$ as Verbal Verb-Forms in Middle Egyptian,” JEA 76 : 73-85.

Depuydt, L. 1983: “The Standard Theory of the 'Emphatic' Forms in Classical (Middle) Egyptian: A Historical Survey," OLP 14 : 13-54.

Englund, G. 1988 : Middle Egyptian: An Introduction, Uppsala.

Gardiner, A. $1957^{3}$ : Egyptian Grammar, Oxford.

Graefe, E. 1987 : Mittelägyptische Grammatik für Anfänger, Wiesbaden.

Graefe, E. $1997^{5}$ : Mittelägyptische Grammatik für Anfänger, Wiesbaden.

Gunn, B. 1924 : Studies in Egyptian Syntax, Paris.

Hoch, J. 1997 : Middle Egyptian Grammar, Toronto.

Junge, F. 1978 : Syntax der mittelägyptischen Literatursprache, Mainz.

Malaise, M. \& Winand, J. 1999: Grammaire raisonnée de l'égyptien classique, Liège.

Ockinga, B. G. 1998: A Concise Grammar of Middle Egyptian, Mainz am Rhein.

Polotsky, H. J. 1944 : Êtudes de syntaxe copte, Cairo.

Polotsky, H. J. 1965 : Egyptian Tenses, IASHP 2/5, Jerusalem.

Polotsky, H. J. 1976: "Les transpositions du verbe en égyptien classique," IOS 6 : 1-50.

Schenkel, W. 1987: Einführung in die klassisch-ägyptische Sprache und Schrift, Tübingen.

Schenkel, W. 1991: Tübinger Einführung in die klassisch-ägyptische Sprache und Schrift, Tübingen.

Schenkel, W. 1997: Tübinger Einführung in die klassisch-ägyptische Sprache und Schrift, Tübingen.

Vernus, P. 1990 : Future at Issue, New Haven. 
Zonhoven, L. M. J. 1992 : Middel-Egyptische Grammatica: Een praktische Inleiding in Egyptische Taal en het Hiërogliefenschrift, Leiden.

秋山慎一 1998：『やさしいヒエログリフ講座』原書房.

現代言語学辞典 1988 ：『現代言語学辞典』成美堂.

西村洋子 1998 :『古代エジプト語基本単語集』平凡社.

吉成董 1988 :『ヒエログリフ入門』六興出版.

本稿の引用においては, 研究者のあいだにある転字の方法や文法用語の差異は, 筆者 が統一した。また, 本稿は平成11年度関西大学学部共同研究費による成果の一部であ る。 